\title{
Model Pemeliharaan Infrastruktur Embung Berbasis Biaya Siklus Hidup Di Kabupaten Sleman DIY
}

\section{Embung Infrastructure Maintenance Model based on Life Cycle Cost in Sleman Regency DIY}

\author{
Floren $^{1, a)}$, Peter F. Kaming ${ }^{1)}$ \& Wulfram I. Ervianto ${ }^{1)}$ \\ 1) Jurusan Teknik Sipil, Fakultas Teknik, Pascasarjana, Universitas Atma Jaya Yogyakarta, \\ Yogyakarta. \\ Koresponden : ${ }^{a}$ florendidi@gmail.com.
}

\begin{abstract}
ABSTRAK
Dari tahun 2015 hingga 2018 jumlah embung yang berhasil dibangun Kementerian Pekerjaan Umum dan Perumahan Rakyat (PUPR) sebanyak 2.722 diseluruh Indonesia. Seiring meningkatnya jumlah tampungan air yang dibangun maka diperlukan suatu kegiatan pemeliharaan yang terencana untuk mendukung pertumbuhan dan perkembangan pemanfaatan embung. Kegiatan pemeliharaan adalah salah satu rantai penting dalam pengelolaan embung karena tanpa adanya kegiatan pemeliharaan yang memadai dan terencana dengan baik maka akan ada banyak dampak negatif yang akan ditimbulkan. Bertolak dari latar belakang yang telah diuraikan maka perlu dilakukan penelitian untuk membahas tentang model pemeliharaan berbasis Life Cycle Cost (LCC) untuk infrastruktur embung di Kabupaten Sleman DIY dengan harapan dapat mengkaji model pemeliharaan dan perawatan embung sehingga diketahui komponen komponen apa saja yang memerlukan pemeliharaan dan perawatan baik secara rutin maupun berkala serta service life setiap komponen agar kegiatan pemeliharaan terlaksana secara optimal dan efisien. Dari hasil analisis didapat bahwa ada lima komponen biaya yang menyusun $L C C$ pada embung dan biaya rata-rata tiap komponen yaitu: biaya pembangunan $43.67 \%$, biaya pemeliharaan rutin 27.12 , biaya pemeliharaan berkala $14.27 \%$, biaya Penggantian $8.33 \%$ dan biaya operasional $6.59 \%$.
\end{abstract}

Kata Kunci : manajemen infrastruktur, embung, pemeliharaan, biaya siklus hidup, service life.

\section{PENDAHULUAN}

Menurut Direktorat Pengelolaan Air di Indonesia kebutuhan air untuk irigasi mencapai $81,4 \%$ dari total kebutuhan air, dimana sektor pertanian adalah pemakai terbanyak dari kebutuhan air tersebut. Untuk mencapai peningkatan hasil pertanian diperlukan sistem pendukung seperti infrastruktur yang memadai. Dalam rangka mencapai ketahanan air dan kedaulatan pangan, Kementerian Pekerjaan Umum dan Perumahan Rakyat (PUPR) terus meningkatkan jumlah tampungan air melalui pembangunan bendungan dan embung di seluruh Indonesia. Tahun 2015-2016 terdapat 719 embung baru yang tersebar diseluruh wilayah Indonesia berhasil diselesaikan oleh kementerian PUPR. Pada tahun 2017 kementerian PUPR mentargetkan akan menyelesaikan 111 embung baru dan memasuki tahun 2018 total embung yang ada telah mencapai 2.722. (PUPR 2017).

Untuk mendukung pertumbuhandan perkembangan pemanfaatan embung sangat ditentukan dari pengelolaannya. Kegiatan pemeliharaan adalah salah satu rantai penting dalam pengelolaan embung karena tanpa adanya kegiatan pemeliharaan yang memadai dan 
terencana dengan !baik maka dampak negatif yang akan ditimbulkan antara lain: kerusakan embung sebelum tercapai umur rencana, terganggunya keberadaan dan fungsi sumber air/lingkungan, beban biaya rehabilitasi/ peningkatan semakin berat dari waktu ke waktu, menurunnya kinerja pelayanan kepada masyarakat, dan kegagalan tujuan pembangunan. (Soemitro \& Suprayitno 2018; Suprayitno \& Soemitro 2018).

Mengingat pembangunan embung yang terus meningkat jumlahnya di Indonesia dan pentingnya pemeliharaan terhadap embung-embung yang telah dibangun tersebut maka pemeliharaan harus menjadi perhatian yang serius agar pemanfaatannya menjadi maksimal. Bertolak dari latar belakang yang telah diuraikan maka perlu dilakukan penelitian untuk membahas tentang model pemeliharaan berbasis life cycle cost (LCC) untuk embung di Kabupaten Sleman DIY, dengan harapan dapat mengkaji model pemeliharaan dan perawatan embung sehingga diketahui komponen komponen apa saja yang memerlukan pemeliharaan dan perawatan baik secara rutin maupun berkala agar terlaksana secara optimal dan efisien.

Penelitian ini dilakukan pada tiga embung yang terletak di Kabupaten Sleman Daerah Istimewa Yogyakarata yaitu Embung Tambakboyo, Embung Serut dan Embung Sendari. Ketiga embung ini telah beroperasi lebih dari lima tahun.

Berdasarkan latar belakang tersebut diatas, maka permasalahan pada penelitian ini dapat dirumuskan sebagai berikut :

Komponen-komponen apa saja yang memerlukan pemeliharaan dan perawatan pada embung baik secara rutin maupun secara berkala?

a. Berapa umur layanan (service life) atau periode layanan (periodic service) setiap komponen perawatan embung?

b. Bagaimana merancang Life Cycle Cost (LCC) untuk perawatan dan pemeliharaan Infrastruktur Embung?

Adapaun tujuan yang ingin dicapai pada penelitian ini terdiri dari 3 tujuan utama sebagai berikut.

a. Untuk mengetahui komponen-komponen apa saja yang membutuhkan pemeliharaan dan perawatan baik secara rutin maupun secara berkala pada embung.

b. Untuk mengetahui umur layanan (service life) atau periode layanan (periodic service) setiap komponen pemeliharaan embung.

c. Untuk merancang life cycle cost (LCC) pemeliharaan dan perawatan embung.

\section{TINJAUAN PUSTAKA}

\section{Embung}

Defenisi embung berdasarkan buku Pedoman Teknis Konservasi Air Melalui Pembangunan Embung yang diterbitkan oleh Direktorat Pengelolaan Air Irigasi, pada tahun 2011 adalah bangunan konservasi air berbentuk cekungan disungai atau aliran air berupa urugan tanah, urugan batu, beton dan/atau pasangan batu yang dapat menahan dan menampung air untuk berbagai keperluan. Berdasarkan Peraturan Menteri Pekerjaan Umum nomor 32/PRT/M/2007 pemeliharaan jaringan irigasi adalah upaya menjaga dan mengamankan jaringan irigasi agar selalu dapat berfungsi dengan baik guna memperlancar pelaksanaan operasi dan mempertahankan kelestariannya melalui kegiatan perawatan, perbaikan, pencegahan dan pengamanan yang harus dilakukan secara terus menerus.

Secara umum kegiatan pemeliharaan terdiri dai 2 (dua) jenis, yaitu Pemeliharaan Pencegahan (Preventif) dan Pemeliharaan Perbaikan (Korektif).

a. Pemeliharaan Pencegahan (Preventif) merupakan kegiatan pemeliharaan untuk tujuan mencegah terjadinya kerusakan dan kemunduran fungsi bangunan, baik yang dilakukan secara rutin atau dengan selang waktu tertentu. 
b. Pemeliharaan Perbaikan (Korektif) merupakan pekerjaan' pemeliharaan yang bertujuan mengembalikan kondisi dan fungsi bangunan seperti kondisi dan fungsi bangunan pada saat dibangun.

Ilustrasi Tipe Pekerjaan Pemeliharaan, baik Pemeliharaan Preventif maupun Pemeliharaan Korektif disampaikan pada Gambar 1 sebagai berikut.

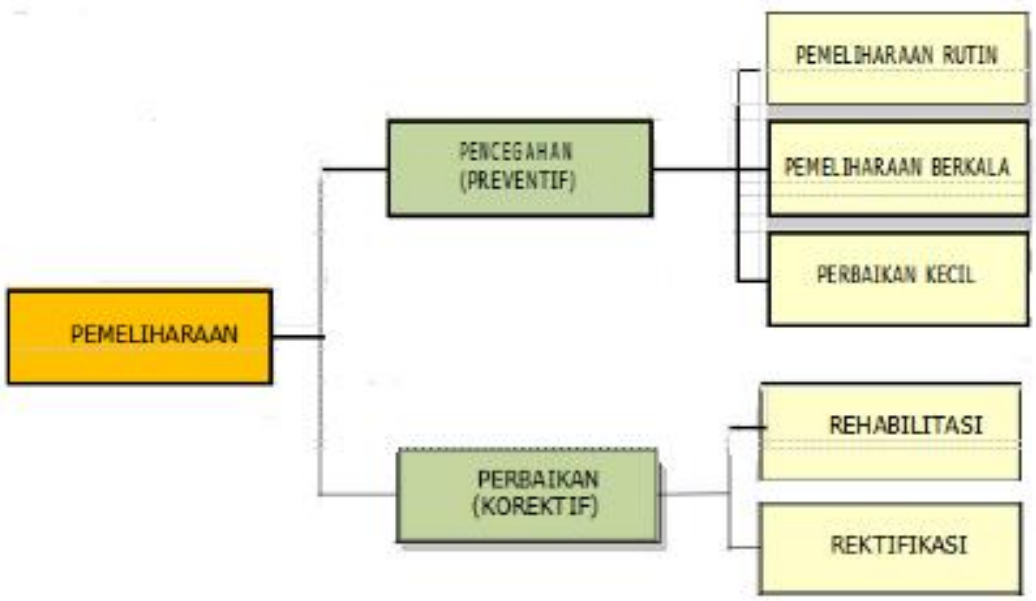

(Sumber: Buku Saku O\&p Embung Balai Besar Wilayah Sungai Serayu Opak, 2018)

Gambar 1. Kegiatan Pemeliharaan Pada Embung

\section{Analisis Harga Satuan Pekerjaan (AHSP)}

\section{Operasional dan Pemeliharaan (OP) Embung}

Penyusunan harga satuan pekerjaan OP embung ini menggunakan berbagai referensi yang diacu diantaranya Permen PU No 11 tahun 2013 tentang Analisis Harga Satuan Pekerjaan Bidang Pekerjaan Umum khususnya bagian 2, AHSP Bidang Sumber Daya Air dan pengalaman pelaksanaan pekerjaan di lapangan serta . Untuk hal-hal tertentu yang belum tercantum dalam pedoman ini masih dimungkinkan untuk dibuat AHSP berdasarkan referensi lain atas persetujuan direksi pekerjaan. (BBWS Serayu Opak 2018).

Satu hal yang tidak kalah penting adalah perhitungan AHSP. Koefisien analisa harga satuan adalah angka - angka jumlah kebutuhan bahan maupun tenaga yang diperlukan untuk mengerjakan suatu pekerjaan dalam satu satuan tertentu. koefisien analisa harga satuan berfungsi sebagai pedoman awal perhitungan rencana anggaran biaya bangunan, kondisi tersebut membuat koefisien analisa harga satuan menjadi kunci menghitung dengan tepat perkiraan anggaran biaya bangunan. Adapun cara untuk mencari koefisien analisa harga satuan rencana anggaran biaya bangunan adalah :

1. Melihat Standar Nasional Indonesia ( SNI )

Standar nasional (SNI) ini di keluarkan resmi oleh badan standarisasi nasional, dikeluarkan secara berkala sehigga SNI tahun terbaru merupakan revisi edisi SNI sebelumya. untuk memudahkan mengetahui edisi yang terbaru, SNI ini diberi nama sesuai tahun terbitnya misal : SNI 1998, SNI 2002, SNI 2007).

2. Pengamatan dan Penelitian Langsung di Lapangan

Cara ini cukup merepotkan dan membutuhkan cukup banyak waktu, tapi hasilnya akan mendekati ketepatan karena diambil langsung dari pengalama kita dilapangan, caranya dengan meneliti kebutuhan bahan, waktu dan tenaga pada suatu pekerjaan yang sedang dilaksanakan. 


\section{Life Cycle Cost (LCC)}

Life Cycle Cost adalah total biaya yang dikeluarkan sepanjang siklus hidup suatu sistem yang langsung berhubungan dengan biaya kepemilikan selama umur ekonomis. Konsep Life Cycle Cost adalah sebuah proses untuk menentukan biaya paling efektif diantara banyak alternatif yang tersedia (Dell'Isola, 1995). Sedangkan Menurut (Pujawan, 2004), Biaya siklus hidup (Life Cycle Cost) dari suatu item adalah jumlah semua pengeluaran yang berkaitan dengan item tersebut sejak dirancang sampai tidak terpakai lagi.

Berdasarkan pendapat para ahli diatas life cycle cost dapat dirumuskan dengan menggunakan persamaan sebagai berikut. sebagai berikut

LCC $=$ Biaya Awal + Biaya Penggunaan + Biaya Perawatan dan Penggantian Dimana :

Biaya awal

Biaya Penggunaan
: Biaya perencanaan dan pelaksanaan bangunan : Biaya yang digunakan selama bangunan beroperasi

Biaya Perawatan dan Penggantian : Biaya untuk perawatan dan penggantian Komponen - Komponen penyusun bangunan selama Umur Rencana Bangunan

\section{METODOLOGI PENELITIAN}

Penelitian tentang pemeliharaan Embung dilakukan dengan mengikuti langkahlangkah sebagai berikut :

a. Observasi

Penulis melakukan pengamatan langsung ke lapangan serta melakukan wawancara dengan pengelola embung untuk mengetahui masalah terkait pemeliharaan embung.

b. Identifikasi Masalah

Berdasarkan informasi tentang permasalahan yang ada dilapangan mengenai pemeliharaan embung penulis selanjutnya merumuskan masalah dan menentukan tujuan penelitian.

c. Studi Pustaka

Studi pustaka dilakukan untuk mengumpulkan referensi pendukung dengan membaca jurnal, peraturan pemerintah, karya ilmiah berita di internet dan buku-buku yang terkait dengan masalah dan tujuan penelitian.

d. Pengumpulan Data

Pengumpulan data primer dilakukan menggunakan kuisioner yang disebarkan kepada 30 Responden. Responden pada penelitian ini adalah semua pihak yang terlibat dalam usaha pemeliharaan embung. Sedangkan data sekunder berupa shop drawing sebagai acuan pelaksanaan pekerjaan embung, tabel harga satuan pekerjaan hasil survey komponen DKPB Kabupaten Sleman tahun 2015, serta Rincian Anggaran Biaya (RAB) embung. Data sekunder bersumber dari Satuan Kerja Balai Besar Wilayah Sungai Serayu-Opak.

Setelah pengumpulan data kuisioner dilakukan untuk mengetahui umur layanan (service life) komponen pemeliharaan embung, kemudian hasil survey disajikan dalam tabel rangkuman yang meliputi rangkuman data responden. Teknik analisis data yang digunakan pada penelitian ini yaitu analisis deskriptif.

1. Mean

Mean adalah nilai rata-rata dari beberapa buah data. Nilai mean dapat ditentukan dengan membagi jumlah data dengan banyaknya data. Dengan kata lain jika kita 
memiliki $\mathrm{N}$ data sebagai berikut maka mean data tersebut dapat kita tuliskan sebagai berikut.

$\bar{x}=\frac{\sum_{i=1}^{N} x i}{N}$

Dimana :

$$
\begin{aligned}
& \bar{x}=\text { nilai mean (rata-rata) } \\
& \mathrm{n}=\text { banyaknya data } \\
& x i=\text { Nilai factor pada responden ke-I }
\end{aligned}
$$

2. Standar Deviasi

Untuk melengkapi analisis data yang telah dikumpulkan, maka akan lebih akurat apabila diukur juga besar kecilnya penyimpangan yang terjadi. Karena seringkali pengukuran dengan mean cenderung menghasilkan hasil yang sama, tetapi mempunya simpangan yang berbeda. Besarnya standar deviasi menunjukkan tinggi rendahnya perbedaan data yang telah diperoleh. Rumus standar deviasi adalah sebagai berikut :

$$
S D=\frac{\sum_{i=1}^{n}(x i-\bar{x})}{\mathrm{n}-1}
$$

Dimana :

$$
\begin{aligned}
\mathrm{SD} & =\text { Standar deviasi } \\
x i & =\text { Nilai factor pada responden ke-i } \\
\bar{x} & =\text { Nilai mean (Rata-rata) } \\
\mathrm{n} & =\text { banyaknya data }
\end{aligned}
$$

3. Analisis Life Cycle Cost Embung

Setelah analisis data kuisioner dilakukan untuk menentukan umur layanan (service life) komponen pemeliharaan embung maka dilanjutkan merancang life cycle cost (LCC) untuk embung selama 25 tahun menggunakan model ISO 15686 dengan bantuan perangkat lunak microsoft excel.

\section{PEMBAHASAN}

Penyebaran kuisioner dilakukan untuk mengetahui service life dari tiap-tiap komponen perawatan pada embung. Dari 30 responden yang mengisi kuisioner didapat nilai penyimpangan baku (standar deviasi) dan nilai rata-rata (Mean) untuk service life dari komponen-komponen perawatan dan pemeliharaan embung dan seperti yang terdapat pada tabel dibawah ini : 
Tabel 1. Data Nilai Rata-Rata, Standar Deviasi dan Service Life

\begin{tabular}{|c|c|c|c|c|}
\hline No & Kegiatan & Mean & Standar deviasi & Service Life \\
\hline \multicolumn{5}{|c|}{ Kegiatan Pemeliharaan Rutin (Bulan) } \\
\hline 1 & Membersihan jalan dari sampah & 4.5 & 0.3026 & 4 \\
\hline 2 & $\begin{array}{l}\text { Babat rumput pada Dinding tanggul/tebing embung, } \\
\text { saluran embung serta jalan inspeksi dari rumput }\end{array}$ & 2.75 & 0.6721 & 3 \\
\hline 3 & Pembersihan Saluran serta kolam tampungan dari sampah & 3.5 & 0.197 & 4 \\
\hline 4 & Memberikan minyak pelumas pada pintu air & 6.28 & 0.214 & 6 \\
\hline \multicolumn{5}{|c|}{ Kegiatan Pemeliharaan Berkala (Tahun) } \\
\hline 1 & Penambalan jalan yang berlubang & 2 & 0.108 & 2 \\
\hline 2 & Memperbaiki rongga/ kebocoran dinding kolam & 1 & 0.1216 & 1 \\
\hline 3 & Pengerukan saluran dan kolam embung dari sedimen & 12 & 0.1632 & 12 \\
\hline 4 & Perbaikan bocoran/ retakan pada bangunan spillway & 11.25 & 0.1537 & 11 \\
\hline 5 & Pengecetan pintu intake & 1.37 & 1.09 & 1 \\
\hline 6 & Pengecetan mistar ukur & 1.42 & 0.1095 & 1 \\
\hline 7 & Pengecetan Ulang gedung kantor & 1.37 & 0.45 & 1 \\
\hline 8 & Pengecetan pagar keliling embung & 1.37 & 0.36 & 1 \\
\hline 9 & Pengecetan ulang papan nama & 1.375 & 0.1503 & 1 \\
\hline \multicolumn{5}{|c|}{ Kegiatan Penggantian (Tahun) } \\
\hline 1 & Penggantian Pintu air & 16.25 & 0.4341 & 16 \\
\hline 2 & Penggantian Saringan intake & 13.75 & 0.3821 & 14 \\
\hline 3 & Penggantian mistar Ukur & 12.5 & 0.3714 & 13 \\
\hline 4 & Penggantian lampu kantor & 4.33 & 0.2421 & 4 \\
\hline 5 & Penggantian papan nama & 10 & 1.04 & 10 \\
\hline
\end{tabular}

Selanjutnya dari analisis Kuisioner diperoleh service life dari nilai Mean untuk menghitung life cycle cost pada embung. Uraian LCC pada Embung Serut, Embung Sendari, dan Embung Tambakboyo dapat dilihat pada tabel dibawah. 
Tabel 2. Biaya Siklus Hidup

\begin{tabular}{|c|c|c|c|c|c|c|}
\hline Kegiatan & $\begin{array}{l}\text { Service } \\
\text { Life }\end{array}$ & $\begin{array}{l}\text { Harga } \\
\text { Satuan }\end{array}$ & $\begin{array}{l}\text { Volu } \\
\text { me }\end{array}$ & $\begin{array}{l}\text { Frekuensi } \\
25 \text { Tahun }\end{array}$ & Jumlah & Total \\
\hline \multicolumn{7}{|l|}{ Biaya Pemeliharaan Rutin } \\
\hline \multicolumn{7}{|l|}{ - Babat rumput pada Dinding } \\
\hline $\begin{array}{ll} & \text { tanggul/tebing embung, saluran } \\
& \text { embung serta jalan inspeksi dari rumput }\end{array}$ & $3 \mathrm{bln}$ & Rp. 3,515; & & 100 & Rp.307,281,300; & \\
\hline $\begin{array}{l}\text { - Pembersihan Saluran serta kolam } \\
\text { tampungan dari sampah }\end{array}$ & 4 bln & Rp. 3,515; & $4371 \mathrm{~m} 2$ & 75 & Rp.1,152,304,875; & \\
\hline $\begin{array}{l}\text { - Memberikan minyak pelumas pada } \\
3 \text { pintu air }\end{array}$ & $6 \mathrm{bln}$ & Rp. 97,500; & $1 \mathrm{bh}$ & 12.5 & Rp.1,218,750; & Rp.1,361,752,225; \\
\hline \multicolumn{7}{|l|}{ Biaya Pemeliharaan Berkala } \\
\hline $\begin{array}{l}\text { - Penambalan jalan yang berlubang, } \\
\text { becek dll }\end{array}$ & 2 thn & Rp. 145,017; & & 12 & Rp.208,955,715; & \\
\hline $\begin{array}{l}\text { - Memperbaiki rongga/ kebocoran } \\
\text { dinding kolam }\end{array}$ & 1 thn & Rp. 43,491; & & 25 & Rp.57,918,595; & \\
\hline 3 - Pengecetan pintu intake & 1 thn & Rp. 46,397; & $6.11 \mathrm{~m} 2$ & 25 & Rp.7,087,218; & \\
\hline $\begin{array}{l}\text { - Pengerukan saluran dan kolam } \\
\text { embung dari sedimen }\end{array}$ & 12 thn & Rp. 35,634; & $4371 \mathrm{~m} 2$ & 2 & Rp.311,520,385; & \\
\hline $\begin{array}{l}\text { - Perbaikan bocoran/ retakan pada } \\
\text { bangunan spillway }\end{array}$ & 11 thn & Rp. 43,491; & $1836 \mathrm{~m} 2$ & 2 & Rp.159,698; & \\
\hline 6 - Pengecetan pagar keliling embung & 1 thn & Rp. 46,397; & $135 \mathrm{~m} 2$ & 25 & Rp.156,591,562; & \\
\hline - Pengecetan ulang papan nama & 1 thn & Rp. 51,611; & $2 \mathrm{~m} 2$ & 25 & Rp.2,580,554; & \\
\hline - Pengecetan ulang mistar ukur & 1 thn & Rp. 51,611; & $1 \mathrm{bh}$ & 25 & Rp.1,290,277; & \\
\hline 8 - Pengecetan Ulang gedung kantor & 1 thn & Rp. 13,581; & & 25 & - & Rp.746,104,007; \\
\hline \multicolumn{7}{|l|}{ Biaya Penggantian } \\
\hline $\begin{array}{l}\text { - Penggantian paving blok secara } \\
\text { keseluruhan }\end{array}$ & 6 thn & Rp.145,017; & & 4 & Rp.464,346,035; & \\
\hline - Penggantian Pintu air & 16 thn & Rp.3,158,275; & $1 \mathrm{~m} 2$ & 1 & Rp. $3,158,275$ & \\
\hline 2 - Saringan intake & 14 thn & Rp. 867,125 & & - & - & \\
\hline - Mistar Ukur & 13 thn & Rp.270,474; & $1 \mathrm{bh}$ & 1 & Rp.270,474; & \\
\hline 3 - Papan nama & 10 thn & Rp.535,945; & $1 \mathrm{bh}$ & 2 & Rp.1,071,890; & \\
\hline 4 - Lampu kantor & 4 thn & Rp.204,000; & & 6 & - & Rp.468,846,674; \\
\hline \multicolumn{7}{|l|}{ Biaya Operasional } \\
\hline 1 - Juru Operasi \& Pemeliharaan & $1 \mathrm{OB}$ & Rp.1,600,000; & & 300 & Rp. $480,000,000$ & \\
\hline 2 - Alat kebersihan dan Bahan & $1 \mathrm{Ls}$ & Rp. 200,000; & & 100 & Rp.20,000,000; & \\
\hline 3 - Alat Tulis Kantor (ATK) & $1 \mathrm{Ls}$ & Rp. 200,000; & & 300 & Rp.60,000,000; & \\
\hline $4 \quad$ Listrik & & - & & - & - & \\
\hline \multirow[t]{2}{*}{ Biaya Pembangunan } & & & & & & Rp.4,301,479,166; \\
\hline & & & & & & Rp.7,438,181,968; \\
\hline
\end{tabular}


Tabel 4. Life Cycle Cost pada Embung Tambakboyo

\begin{tabular}{|c|c|c|c|c|c|c|c|}
\hline No & Kegiatan & Life & $\begin{array}{l}\text { Harga } \\
\text { Satuan }\end{array}$ & Volume & $\begin{array}{c}25 \\
\text { Tahun }\end{array}$ & Jumlah & Total \\
\hline 1 & $\begin{array}{l}\text { Babat rumput pada Dinding } \\
\text { tanggul/tebing embung, saluran } \\
\text { embung serta jalan inspeksi dari } \\
\text { rumput }\end{array}$ & $\mathrm{i}_{3} \mathrm{bln}$ & Rp.3,515; & $30840 \mathrm{~m} 2$ & 100 & Rp.10,840,260,000; & \\
\hline 2 & $\begin{array}{l}\text { Pembersihan Saluran serta } \\
\text { kolam } \\
\text { tampungan dari sampah }\end{array}$ & 4 bln & Rp.3,515; & $117000 \mathrm{~m} 2$ & 75 & Rp.30,844,125,000; & \\
\hline 3 & $\begin{array}{l}\text { Memberikan minyak pelumas } \\
\text { pada pintu air }\end{array}$ & 6 bln & Rp.97,500; & $5 \mathrm{bh}$ & 12.5 & Rp.6,093,750; & \\
\hline 1 & $\begin{array}{l}\text { Penambalan jalan yang } \\
\text { berlubang, becek dll }\end{array}$ & 2 thn & Rp.145,017; & $4617 \mathrm{~m} 2$ & 12 & Rp.8,034,706,188; & \\
\hline 2 & $\begin{array}{l}\text { Memperbaiki rongga/ } \\
\text { kebocoran dinding kolam }\end{array}$ & 1 thn & Rp.43,491; & $8700 \mathrm{~m} 2$ & 25 & Rp.9,459,292,500; & \\
\hline 3 & Pengecetan pintu intake & 1 thn & Rp.46,397; & $12.5 \mathrm{~m} 2$ & 25 & Rp.14,499,218; & \\
\hline 4 & $\begin{array}{l}\text { Pengerukan saluran dan kolam } \\
\text { embung dari sedimen }\end{array}$ & 12 thn & Rp.35,634; & $117000 \mathrm{~m} 2$ & 2 & Rp.8,338,568,991; & \\
\hline 5 & $\begin{array}{l}\text { Perbaikan bocoran/ retakan } \\
\text { pada bangunan spillway }\end{array}$ & 11 thn & Rp.43,491; & $33.75 \mathrm{~m} 2$ & 2 & Rp.2,935,642; & \\
\hline 6 & $\begin{array}{l}\text { Pengecetan pagar keliling } \\
\text { embung }\end{array}$ & 1 thn & Rp.46,397; & $1450 \mathrm{~m} 2$ & 25 & Rp.1,681,909,375; & \\
\hline \multirow{2}{*}{7} & \multirow{2}{*}{$\begin{array}{l}\text { Pengecetan ulang papan nama } \\
\text { Pengecetan ulang mistar ukur }\end{array}$} & 1 thn & Rp.51,611; & $8.00 \mathrm{~m} 2$ & 25 & Rp.10,322,217; & \multirow[b]{3}{*}{ Rp.47,122,414,391; } \\
\hline & & 1 thn & Rp.51,611; & $1 \mathrm{~m} 2$ & 25 & Rp.1,290,277; & \\
\hline 8 & $\begin{array}{l}\text { Pengecetan Ulang gedung } \\
\text { kantor }\end{array}$ & 1 thn & Rp.13,581; & $360 \mathrm{~m} 2$ & 25 & Rp.122,229,000; & \\
\hline \multirow{4}{*}{1} & & 6 thn & Rp.145,017; & $30780.6 \mathrm{~m} 2$ & 4 & Rp.17,854,902,642; & \\
\hline & $\begin{array}{l}\text { Penggantian paving blok secara } \\
\text { keseluruhan }\end{array}$ & 16 thn & Rp.3,158,275; & $12.5 \mathrm{~m} 2$ & 1 & Rp.39,478,437; & \\
\hline & Saringan intake & 14 thn & Rp. 867,125; & $35 \mathrm{~m} 2$ & - & Rp. 30,349,375; & \\
\hline & & 13 thn & Rp.270,474; & $1 \mathrm{bh}$ & 1 & Rp. 270,474; & \\
\hline 3 & Papan nama & 10 thn & Rp.535,945; & - & 2 & - & \multirow{2}{*}{ Rp.17,940,300,928 } \\
\hline 4 & Lampu kantor & 4 thn & Rp.204,000; & $5 \mathrm{bh}$ & 6 & Rp. 15,300,000; & \\
\hline
\end{tabular}

\section{Biaya Operasional}

\begin{tabular}{llcrccc}
\hline 1 & Juru Operasi & 1 bln & Rp.1,600,000; 2 OB & 300 & Rp. 480,000,000; \\
\hline 2 & Juru Pemeliharaan & 1 bln & 4 OB & - & - \\
\hline 3 & Petugas Kemanan & 1 bln & 2 OB & - & - \\
\hline 4 & Alat kebersihan dan Bahan & 1 bln & Rp.200,000; 4 Ls & 100 & Rp.20,000,000; \\
\hline
\end{tabular}




\begin{tabular}{llllllll}
5 & Alat Tulis Kantor (ATK) & 1 bln & Rp.200,000; & 1 Ls & 300 & Rp.60,000,000; \\
\cline { 1 - 5 } 6 & Listrik & 1 bln & Rp.600,000; 1 & 300 & Rp. 180,000,000 & \\
\cline { 1 - 5 } 7 & PDAM & 1 bln & Rp.500,000; 1 & 300 & Rp. 150,000,000 & Rp.4,310,000,000 \\
\hline Biaya Pembangunan & & & & & Rp. $51,572,005,245 ;$ \\
\hline
\end{tabular}

Dari hasil analisis LCC ketiga embung diatas dapat dilihat perbandingan inisial cost masing-masing komponen tiap embung pada tabel dibawah ini.

Tabel 5. Tabel perbandingan inisial cost komponen LCC Embung Serut, Embung Tambakboyo dan Embung Sendari

\begin{tabular}{|c|c|c|c|c|c|}
\hline No & Inisial Cost & Embung Serut (\%) & $\begin{array}{c}\text { Embung } \\
\text { Tambakboyo (\%) }\end{array}$ & $\begin{array}{c}\text { Embung Sendari } \\
(\%)\end{array}$ & Rata-Rata (\%) \\
\hline 1 & $\begin{array}{l}\text { Biaya } \\
\text { Pembangunan }\end{array}$ & 37.17 & 36.02 & 57.83 & 43.67 \\
\hline 2 & $\begin{array}{l}\text { Biaya } \\
\text { Pemeliharaan } \\
\text { Rutin }\end{array}$ & 33.95 & 29.12 & 18.31 & 27.12 \\
\hline 3 & $\begin{array}{l}\text { Biaya } \\
\text { Pemeliharaan } \\
\text { Berkala }\end{array}$ & 13.45 & 19.32 & 10.03 & 14.27 \\
\hline 4 & Biaya Penggantian & 6.15 & 12.53 & 6.3 & 8.33 \\
\hline 5 & Biaya Operasional & 9.24 & 3.01 & 7.53 & 6.59 \\
\hline & Total & 100 & 100 & 100 & 100 \\
\hline
\end{tabular}

\section{PENUTUP}

\section{Kesimpulan}

Dari hasil penelitian dan pembahasan yang telah dilakukan pada tiga embung yang berada di Kabupaten Sleman Daerah Istimewa Yogyakarta yaitu Embung Serut, Embung Tambakboyo dan Embung Sendari dapat disimpulkan bahwa :

1. Biaya pembangunan merupakan setengah dari seluruh biaya yang menyusun siklus hidup suatu embung.

2. Terdapat 5 komponen biaya yang menyusun Biaya Siklus Hidup pada embung yaitu Biaya Pembangunan, Biaya Pemeliharaan Rutin, Biaya Pemeliharaan Berkala, Biaya Penggantian dan Biaya Operasional. Biaya rata - rata tiap komponen yang menyusun LCC Embung yaitu Biaya Pembangunan 43.67\%, Biaya Pemeliharaan Rutin 27.12, Biaya Pemeliharaan Berkala 14.27\%, Biaya Penggantian 8.33\% dan Biaya Operasional $6.59 \%$.

\section{Saran}

Pada penelitian selanjutnya disarankan untuk melakukan penelitian dengan memisah antara embung-embung berdasarkan fungsinya, misal : embung sebagai konservasi air, embung pertanian, embung pariwisata dan lain-lain. Hal ini di karenakan fungsi embung turut mempengaruhi komponen-komponen pemeliharaan, Penggantian serta operasional pada embung. 


\section{DAFTAR PUSTAKA}

PUPR (2017). Buku Informasi Statistik Kementerian PUPR 2017. Kementerian Pekerjaan Umum \& Perumahan Rakyat. Jakarta.

BBWS Seroya Opak (2018). Buku Saku O \& P Embung. Balai Besar Wilayah Sungai Serayu Opak. Yogyakarta.

PerMen PU 11/13. Peraturan Menteri Pekerjaan Umum Nomor 11 Tahun 2013. tentang Analisis Harga Satuan Pekerjaan Bidang Pekerjaan Umum.

Dell'Isola, S. J. (1995). Life Cycle Costing for Design Professionals. Second Edition. McGraw Hill, Inc. New York.

Direktorat Pengolaan Air Irigasi (2011). Pedoman Teknis Konservasi Air Melalui Pembangunan Embung/Dam Parit. Direktorat Jendral Sarana dan Prasarana Pertanian. Kementerian Pertanian. Jakarta.

PerMen PU 32/07. Peraturan Menteri Pekerjaan Umum Nomor 32 Tahun 2007 tentang Pedoman Operasi dan Pemeliharaan Jaringan Irigasi.

Pujawan, I. N. (2004). Ekonomi Teknik. Widya. Surabaya.

Soemitro, R.A.A. \& Suprayitno, H. (2018). "Pemikiran Awal tentang Konsep Dasar Manajemen Aset Fasilitas". Jurnal Manajemen Aset Infrastruktur \& Fasilitas, Vol.2, Sup.1, Juni 2018, Hal : 1-13.

Suprayitno, H. \& Soemitro, R.A.A. (2018).’Preliminary Reflexion on Basic Principle of Infrastructure Asset Management". Jurnal Manajemen Aset Infrastruktur \& Fasilitas, Vol.2, No.1, Maret 2018, Hal : 1-10. 
